\section{The paradox of access - abortion law, policy and misoprostol}

GLOBAL HELSE

\section{KAREN MARIE MOLAND}

E-mail: Karen.Moland@uib.no

Karen Marie Moland (born 1955) holds a PhD in political science from the University of Bergen. She is a professor at the Centre for International Health, Department of Global Public Health and Primary Care, University of Bergen, Norway.

The author has completed the ICMJE form and reports no conflicts of interest.

\section{HALDIS HAUKANES}

Haldis Haukanes (born 1962) holds a PhD in social anthropology from the University of Bergen, Norway. She is a professor in gender and development at the Department of Health Promotion and Development, University of Bergen, Norway.

The author has completed the ICMJE form and reports no conflicts of interest.

\section{GETNET TADELE}

Getnet Tadele (born 1968) holds a PhD in sociology from the University of Amsterdam and is a professor at the Department of Sociology, Addis Ababa University, Ethiopia.

The author has completed the ICMJE form and reports no conflicts of interest.

\section{ASTRID BLYSTAD}

Astrid Blystad (born 1961) holds a PhD in social anthropology from the University of Bergen. She is a professor at the Centre for International Health, Department of Global Public Health and Primary Care, University of Bergen, Norway.

The author has completed the ICMJE form and reports no conflicts of interest.

The relationship between the law and access to safe abortion services is complex. Country case studies from sub-Saharan Africa show how the political, economic and social contexts in which the laws are embedded often generate unexpected outcomes. 


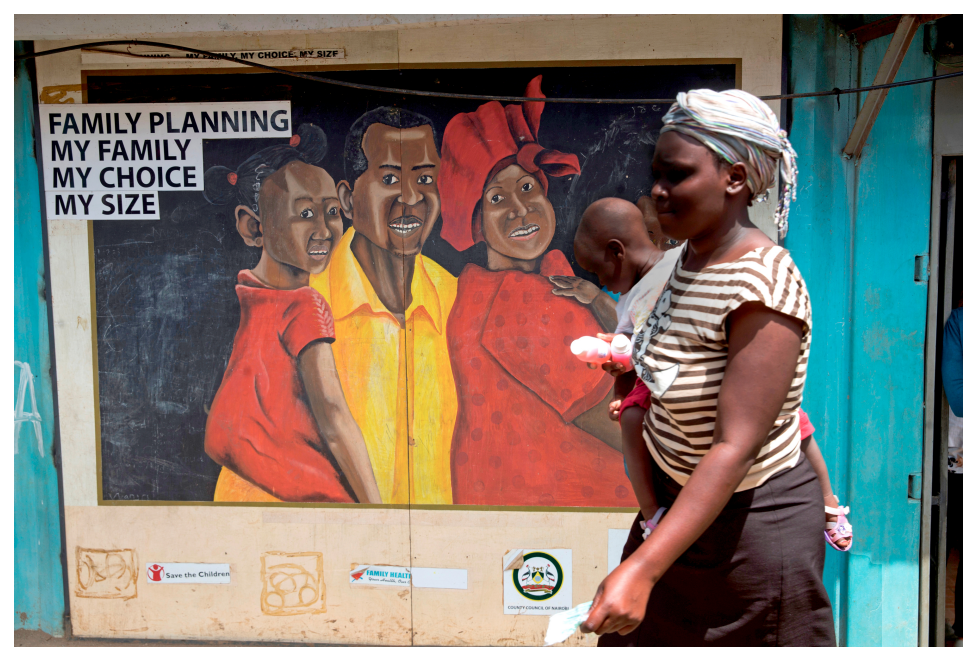

A Family Health Options clinic. Photo: Reuters/Baz Ratner/NTB scanpix

Legal frameworks are recognised as vital for securing the right to health. The articulation between law, health policy and actual access to health services is not a straightforward matter. Unsafe abortion is perhaps one of the most neglected sexual and reproductive health problems in the world today. With almost 22 million cases annually, unsafe abortions contribute substantially to maternal mortality and morbidity rates globally (1). Abortion-related maternal deaths occur predominantly in low-income countries. In subSaharan Africa, deaths due to unsafe abortions have increased steadily since the 199os (2). Abortions currently account for approximately $14 \%$ of the maternal mortality rate (1). Young women are disproportionately affected.

The high rate of unsafe abortions has been referred to as a 'silent pandemic' (3). Unsafe abortions are surrounded by stigma and neglect (4). In global health policy, abortion has been treated with caution, due to its controversial nature. The International Conference on Population and Development Programme of Action in 1995 adopted a human rights-based approach to reproductive health. However, it did not gain sufficient support from member states to include safe abortion as a 'reproductive right'. Rather, it concluded with the weak statement that safe abortion services should be provided 'where legal' and that 'any measures of change related to abortion within the health system can only be determined at the national and local level according to the national legislative process' (5).

In an increasingly conservative policy environment, the Millennium Development Goals in 2001 (6) and more recently the Sustainable Development Goals in 2015 (7), similarly omitted safe abortion from the agenda of reducing maternal mortality. The highly politicised nature of the abortion issue was perhaps most compellingly illustrated by the reinstatement of the 'Mexico City Policy' or the 'global gag rule' by President Trump this year, blocking US funds to organisations involved in abortion service and care (8). It is within this moral-political climate that sub-Saharan countries currently struggle to reduce the high rates of abortionrelated death and illness.

In this chronicle we share our experiences from Ethiopia, Zambia and Tanzania through the Research Council of Norway funded (Norway-Global Partner programme) project 'Safe abortion and fertility control in Ethiopia, Zambia and Tanzania' (SAFEZT).

\section{Law and policy}

It has previously been established that highly restrictive abortion laws are not associated with lower abortion rates (5). Conversely, a liberal abortion law is not a sufficient condition for access to safe abortion services (4). Law and policy on abortion vary greatly between Ethiopia, Zambia and Tanzania, making them interesting comparative cases.

In Zambia, abortion is judicially legal and the law classified as liberal; in Ethiopia, abortion is categorised as illegal, but the stated exceptions make the law appear as semi-liberal; in Tanzania, abortion is illegal and highly restrictive. Considering the status of the abortion 
law, one would expect that women in Zambia would have easiest access to safe abortion services, followed by women in Ethiopia and finally Tanzania, but a complex web of factors mitigate this association.

Of the three countries, Ethiopia has the most progressive policy on safe abortion services. While still classified as illegal in the county's revised criminal code (9), the law permits abortion not only to save the mother's life, but also in the case of rape, incest or minority ( $<18$ years). The abortion-seeker is not required to provide evidence on the circumstances, other than giving a testimony. Technical and Procedural Guidelines for Safe Abortion Services in Ethiopia were issued in 2006 (10). Notably, health workers down to the primary care level have been trained in safe abortion procedures, safe abortion rooms are available in urban and semi-urban areas down to the health centre level, and rates of unsafe abortions have decreased from $73 \%$ in 2010 (11) to $47 \%$ in 2014 (12).

In contrast, in Zambia abortion may legally be carried out on broad health and socioeconomic grounds - under the 1972 Termination of Pregnancy Act (13). However, the law does not translate into safe abortion practices. Access has been made very difficult, particularly for young, poor, rural girls. A written consent from three medical doctors, including a specialist only found in referral hospitals in urban centres is required. New guidelines for safe abortion services were developed in 2009. However, they have not been effectively disseminated and remain largely unfamiliar to doctors. Currently, the prevalence of unsafe abortion in Zambia is reported at $85 \%$ (14). This indicates that an apparent liberal abortion law is far from a sufficient condition to secure access to legal abortion.

Lastly, in Tanzania, the penal code allows abortion only when the life of the mother is in danger (15). In contrast to the complicated consent procedures in Zambia, one health worker's consent is sufficient to obtain an abortion in Tanzania. This leaves room for considerable health worker discretion. No guidelines for safe abortion services exist, and. no incidence data on unsafe abortion are available. However, in response to the highly restrictive law, particularly adolescent women have been shown to resort to illegal abortions provided under unsafe conditions (16).

\section{The paradox of access}

Although high rates of unsafe abortion are - broadly speaking - linked to restrictive abortion laws, the country cases demonstrate that there is an unclear and at times paradoxical association between the status of the law and actual access to safe abortion procedures. The complexity of the relationship between abortion laws, policy and access cannot, however, be fully grasped without recognising how abortion is fundamentally embedded in social, religious and health-system contexts.

Globally, three different discourses dominate the debate on abortion: a human rights discourse, a public health discourse and a religious/moral discourse. In Ethiopia, Zambia and Tanzania the discourse on safe abortion as a 'human right' is largely absent while the discourses on safe abortion as a 'public health' issue and as a 'moral transgression' are competing for prominence. Below we take a look at how these normative discourses are played out and their importance for actual outcomes in the three country contexts.

The official governmental discourse on abortion in Ethiopia is based in public health. Rooted in mortality and morbidity figures related to unsafe abortion, the public health discourse on safe abortion gains legitimacy through the aim of reducing abortion-related death rates, and protecting girls and women from the adverse health consequences of unsafe abortions (1). The changes in the earlier, more restrictive abortion law were fought through in an alliance between civil society actors and the Federal Ministry of Health, promoting safe abortion as a public health measure to reduce maternal mortality.

Different religious groups, particularly the Ethiopian Orthodox Christian Church to which the majority of the population belong, challenge the public health argument and retain the position that abortion is a religious offence and morally wrong. The increasing availability 
of safe abortion services thus to some extent remains silenced, the law is not widely known and high numbers of young women continue to resort to unsafe procedures (12).

The case of Zambia, possibly more than the other two countries, highlights the importance of the religious-moral dimensions of abortion. Zambia has declared itself a Christian nation, the Catholic Church is powerful and the independent churches - including the Pentecostal church - are increasingly visible in the discourse on abortion, promoting a prolife agenda that constructs abortion as a sin and a religious offence. A new bill of rights has recently proposed an amendment to the constitution with vast implications for abortionseeking women stating that: 'The right to life begins at conception' (17).

The ontology of human life and personhood lies at the core of this, as well as of other major abortion controversies. Within the Christian discourse, politicisation and diverse interpretations of the point at which human life begins is particularly pertinent (18). In Zambia, this discourse has opened up for a renewed political dispute over abortion that may curb recent public health efforts to simplify access to safe abortion services in the country.

In Tanzania, where Islam and Christianity are practised by approximately equal proportions of the population, the discourse on abortion as a sin and as a moral transgression predominates at official level. Although the media regularly raises the problem of unsafe abortion-related complications and deaths among young girls, the public health argument is not officially endorsed. Despite the public condemnation there seems to be room for considerable pragmatism, particularly when it comes to the increasing availability and accessibility of misoprostol (19).

\section{The game changer}

WHO has recently promoted medical abortion globally, and more recently misoprostol as a 'harm reduction strategy' that can replace risky abortion procedures worldwide (20).

Studies from South America have documented that self-use of misoprostol obtained from pharmacies reduces abortion-related morbidity and mortality (21). Misoprostol is registered as a drug for post-partum haemorrhage in all three countries, but is not legally marketed for medical abortion purposes. Yet, in Tanzania, emerging evidence suggests that pharmacies and medicine shops across the city of Dar es Salaam offer misoprostol off-label over the counter for abortion purposes (19).

A study in Zambia similarly found that misoprostol was widely available in pharmacies and sometimes prescribed by medical doctors for abortion purposes (19). No study has yet documented access to Misoprostol off-label though pharmacies and medicine shops in Ethiopia.

The rapidly emerging picture globally is that access to misoprostol increases women's power to decide over the timing of their pregnancies. For the individual woman seeking to terminate a pregnancy, abortion may be experienced as morally problematic and contrary to one's faith, but still a better option than bearing the shame and burden of an untimely birth.

The marketing of misoprostol through pharmacies and medicine shops makes it possible to circumvent both the law and gatekeepers in the health system and to access the drug secretly. While this unregulated marketing and unauthorised self-administration of misoprostol involves medical risks, it does also facilitate access to a self-induced abortion procedure that is safer, more private and less invasive than other methods (21).

\section{The relevance of the law}

With misoprostol, yet another factor is added to the complex and paradoxical articulation between law and access to safer abortion procedures that we have sought to illustrate through our country cases. It seems that the abortion law in many countries is lagging 
behind scientific developments (20) as well as the market. Highly restrictive abortion laws may become increasingly irrelevant in determining access to medical abortion procedures in the future.

According to the WHO, unsafe abortion is one of the most easily preventable causes of maternal mortality, but moral and religious reasoning hinders political commitment to address the problem. In order to pay justice to women's reproductive health and rights, access to medical abortion under legal, safe conditions should be prioritised on the global health agenda in the years ahead.

\section{REFERENCES:}

1. World Health Organization. Unsafe abortion: Global and regional estimates of the incidence of unsafe abortion and associated mortality in 2008. Sixth edition, 2011.

http://apps.who.int/iris/bitstream/10665/44529/1/9789241501118_eng.pdf(2.11.2017).

2. Kassebaum NJ, Bertozzi-Villa A, Coggeshall MS et al. Global, regional, and national levels and causes of maternal mortality during 1990-2013: a systematic analysis for the Global Burden of Disease Study 2013. Lancet 2014;384: 980 - 1004. [PubMed][CrossRef]

3. Brookman-Amissah E, Moyo JB. Abortion law reform in sub-Saharan Africa: no turning back. Reprod Health Matters 2004; 12: 227-34. [PubMed][CrossRef]

4. Grimes DA, Benson J, Singh S et al. Unsafe abortion: the preventable pandemic. Lancet 2006; 368 : 1908 - 19. [PubMed][CrossRef]

5. United Nations. Report of the International Conference on Population and Development, Cairo 1994. New York, NY, 1995. https://www.unfpa.org/sites/default/files/event-pdf/icpd_eng_2.pdf (2.11.2017).

6. World Health Organization. Millennium Development Goals. http://www.who.int/topics/millennium_development_goals/maternal_health/en/(22.09.2017).

7. United Nations. Sustainable Development Goals 2015-2030.

http://www.un.org/sustainabledevelopment/sustainable-development-goals/ (22.09.2017).

8. Redden M. Trump expands policy that bans US aid for overseas abortion providers. The Guardian, 15.5.2017. https://www.theguardian.com/world/2017/may/15/trump-abortion-rule-mexico-city-policy (2.11.2017).

9. The Criminal Code of the Federal Democratic Republic of Ethiopia. Proclamation No. 414/2004. http://www.wipo.int/edocs/lexdocs/laws/en/et/eto11en.pdf(2.11.2017).

10. Family Health Department. Addis Ababa. Technical and Procedural Guidelines for Safe Abortion Services in Ethiopia, 2006.

https://srhr.org/abortion-policies/documents/countries/o3-Ethiopia-Technical-and-procedural-guideli nes-for-safe-abortion-services-20o6.pdf(2.11.2017).

11. Singh S, Fetters T, Gebreselassie H et al. The estimated incidence of induced abortion in Ethiopia, 2008. Int Perspect Sex Reprod Health 2010;36:16 - 25. [PubMed][CrossRef]

12. Moore AM, Gebrehiwot Y, Fetters T et al. The Estimated Incidence of Induced Abortion in Ethiopia, 2014: Changes in the Provision of Services Since 2008. Int Perspect Sex Reprod Health 2016; 42: 111 - 20. [PubMed][CrossRef]

13. Government of the Republic of Zambia, Ministry of Legal Affairs. The termination of pregnancy act 1972, ch 304. https://www.zambialii.org/zm/legislation/consolidated_act/304 (2.11.2017).

14. Guttmacher Institute. Unsafe abortion in Zambia. A review of evidence. 2009.

https://www.guttmacher.org/sites/default/files/report_pdf/ib-unsafe-abortion-zambia.pdf(2.11.2017)

15. Government of Tanzania. Tanzania Penal Code, Ch 16 of the Laws (Revised), Issued Under Cap. 1, s 18. 1981. http://www.un.org/depts/los/LEGISLATIONANDTREATIES/PDFFILES/TZA_penal_code.pdf (2.11.2017).

16. Guttmacher Institute. Unsafe abortion in Tanzania. A review of evidence. 2013. 
https://www.guttmacher.org/sites/default/files/report_pdf/ib_unsafe-abortion-tanzania.pdf(2.11.2017).

17. Electoral Commission of Zambia. Understand the 2016 Referendum, Lusaka, 2016

18. Kaufman SR, Morgan L. The anthropology of the beginnings and ends of life. Annu Rev Anthropol 2005; 34:317 - 41. [CrossRef]

19. Buguzi S. The unsafe practice of intended abortion fuelled by drug-stores. The Citizen, 27.2.2017. http://www.thecitizen.co.tz/magazine/The-unsafe-practice-of-intended-abortion-fuelled-by-drug-store s/1840564-3829544-format-xhtml-nfwkat/index.html (22.09.2017).

20. World Health Organization. Safe abortion: technical and policy guidance for health systems. 2012. http://apps.who.int/iris/bitstream/10665/70914/1/9789241548434_eng.pdf. (2.11.2017).

21. Rowlands S. Abortion pills: under whose control? J Fam Plann Reprod Health Care 2012; 38: 117 - 22. [PubMed][CrossRef]

Published: 23 December 2017. Tidsskr Nor Legeforen. DOI: 10.4045/tidsskr.17.0809

Received 20.9.2017, first revision submitted 23.10.2017, accepted 2.11.2017.

(C) The Journal of the Norwegian Medical Association 2020. Downloaded from tidsskriftet.no 